\title{
A facile approach for the preparation of polycarbonate nanofiber mat with filtration capability
}

\author{
Thomas Baby $^{1} \cdot$ Tomlal E. Jose $^{2}$ (D) . C. T. Aravindkumar ${ }^{3} \cdot$ John Richard Thomas $^{3}$
}

Received: 10 December 2019 / Revised: 30 April 2020 / Accepted: 12 June 2020 /

Published online: 22 June 2020

(c) Springer-Verlag GmbH Germany, part of Springer Nature 2020

\begin{abstract}
The present day environmental issues demand a lot from scientists and engineers to keep the planet earth safe for its habitats. There were lot of attempts for developing efficient air and liquid filters as the demand increases with an utmost concern of present environmental situations. Thanks to its large surface area to volume ratio, polymer nanofibers and composites are found to be good substitute for conventional filters. As per the research and analysis data, filtration efficiency increases proportional to the reduction of the average diameter of the fibers. In this study, the most efficient electrospinning technology was adopted to prepare polycarbonate (PC) nanofiber mat which yields a very fine surface morphology. There are earlier researches and associated data available about the preparation of PC nanofibers but with average fiber diameter above $1000 \mathrm{~nm}$. In this study, a systematic methodology was instigated to generate PC nanofibers with least average diameter of $90 \mathrm{~nm}$ without using any surfactants or salts. The most suitable solvents, solvent proportion, polymer concentration and electrospinning conditions for the formation of the fiber mat are discussed elaborately. PC fiber mat of least average diameter was proved to be highly efficient for particulate matter adsorption using a dust sampling analyzer.
\end{abstract}

Keywords Electrospinning $\cdot$ Taylor cone $\cdot$ Beaded fiber $\cdot$ Particulate matter $\cdot$ Fiber mat

Tomlal E. Jose

tomlalj@gmail.com

1 Kuriakose Gregorios College Pampady, Kottayam, Kerala 686502, India

2 St Berchmans College, Changanachery, Kottayam, Kerala 686101, India

3 School of Environmental Sciences, Mahatma University, Kottayam, Kerala 686101, India 


\section{Introduction}

Air pollution is considered as a great curse of twenty-first century as a result of modernization of all levels of present day life. The air quality of New Delhi, India in November 2019 has been created an emergency situation with thousands of people under threat (Fig. 1). The central pollution control board (CPCB) estimated the national capital's average air quality index (AQI) on 3rd Sunday $4.00 \mathrm{pm}$ as 494. The World Health Organization (WHO) perceived air pollution as a dangerous situation that causes premature deaths around seven million every year worldwide. Out of this 2.6 million premature deaths were reported to be of indoor air pollution. Particulate matter in air is the major reason for indoor air pollution and sources include households, agriculture, industry, automobiles, burning of waste and power plants [1-3]. The victims of indoor air pollution are generally children and women. The ramifications and deaths were attributed to be a result of diseases like stroke, pneumonia, pulmonary diseases, lung cancer and heart disease. It was estimated that more than $80 \%$ of the world population are not in a position to access modern technologies. They are still in a situation to depend on inefficient energy sources which again worsen the burning situation.

To use nanofibrous mat as filters for bio-aerosols is a serious concern among scientists particularly during the present outbreak of Covid-19 virus. The potential pandemic has created an emergency situation particularly in the global health care sector. According to WHO the total number of infected COVID 19 cases as on 27th April 2020 were 28,83,603 and killed 1,98,842 people. The Chinese center for disease control and prevention reported that the size of Covid-19 virus is approximately $100 \mathrm{~nm}$. Various types of face masks used for precaution against the virus cannot assure complete protection. WHO has recently given an interim guidance on the use of face masks which emphasized on the standard test methods to ensure the filtration efficiency, fluid penetration resistance and breathability. Virus, allergens, pollens, bacteria and fungus are biological aerosols that result adverse health effects in humans [4]. In this worst scenario, various remediation strategies and measures were being adopted to control air pollution. Microorganisms like viruses usually possess electronegative surface due to the presence of phosphate and carboxyl groups [5]. Most of the nanofibers possess positive charge and that facilitate the effective filtration of viruses and other bio-aerosols $[6,7]$. There were various reports on the
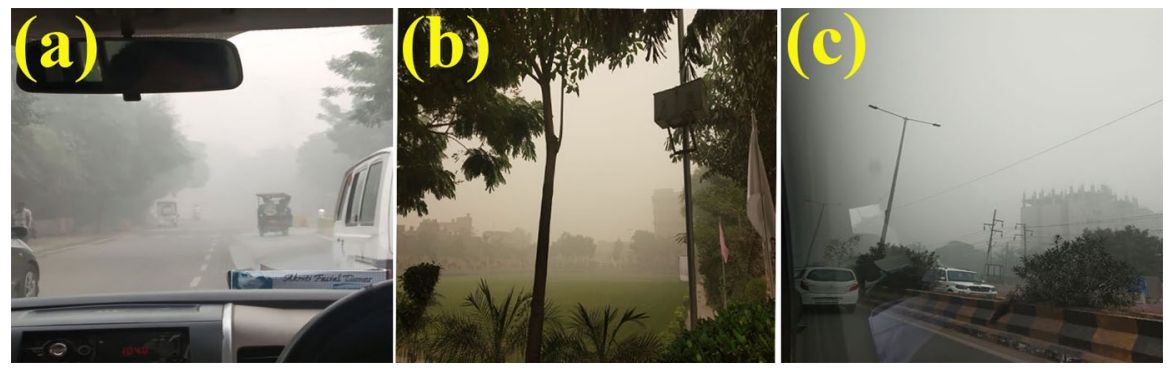

Fig. 1 Some of the air polluted regions of Delhi in 2019 November (a-c) 
preparation of nanofiber filter masks and different filters with improved capacity to filter microbiological objects like viruses [8]. Thinner nanofiber membranes with small pores were made to improve the bacterial retention capacity of sterilizing grade filters [9].

Aerosol filters are the most commonly used technique for purifying and sampling of air. There is a growing demand for innovative and efficient scavenging system for the immediate removal of pollutants contaminated in air. Fibrous filters were found to be highly promising and more efficient than conventional air filters [10-12]. The depth filtration capability of fibrous filters is the resultant of diffusion, inertial impaction, interception and electrostatic interaction [13].

Superior filtration efficiency of ultrafine polymer fiber membranes has been recapitulated as a result of high surface-to-volume ratio, high porosity, microscale interstitial space and interconnectivity $[14,15]$. In filtration field the term nanofiber is attributed to fibers of average diameter well below $500 \mathrm{~nm}$ [16]. There were numerous reports on the diverse applications of nanofiber filter media mainly focused on contaminants and environment. The effective size exclusion nanofibrous mats are well suited for air and water particulate matter removal [17, 18].

Most accepted and well-known method for generating nanofibrous scaffolds for filtration applications is electrospinning. The wide acceptance of this approach is due to its simplicity, cost-effectiveness and the narrow distribution of fiber diameter by which the filtration can be properly controlled [19-21]. Suitable polymer concentration, solvent system, solvent ratio and other spinning parameters are essential for fabricating fibers with least average diameter. The polymer solution taken in the spinneret ejected out of the needle tip by the application of a high electric potential. Both electrical and mechanical forces make use for the ejection of polymer jet from the needle tip. The electrically charged drop at the needle tip assumes a cone shape which is called Taylor cone. This phenomenon is observed when the force due to electric field outweigh the force of surface tension. At this critical electric voltage, the polymer jet starts ejected from the Taylor cone tip. This then undergoes a bending instability and the main jet splits into number of mini jets. Solvent evaporation occurs from the polymer jets during the flight towards the oppositely charged collector [22]. During the movement towards the collector the mini-jets suffer strong competition between different instabilities. This include the whipping instability, Rayleigh instability and axisymmetric conducting mode instability. These instabilities vary depending on the electrospinning and fluid parameters. So optimizing the solution properties and other spinning parameters are crucial for the final morphology of the fibers $[23,24]$.

The flow of polymer jet from the nozzle tip to the collector undergoes variation in current under an applied voltage. This depends on the charge carrying capacity of the polymer solution. There will be a change of shape of polymer jet at the nozzle tip by the increase of the applied electric current. This is considered as a major factor that determines the final surface morphology of the fiber [25]. There are various reports on the deviation of the average diameter of the electrospun fibers by the variation of the applied electric current. The minimum electron volt required for the deposition of ultrafine fibers during electrospinning is directly related to the needle tip-collection plate distance [26-29]. 
Another important factor that influences the fiber morphology is the distance between the tip of the needle and the collecting plate. Depending upon the volatility of the solvent, solvent proportion, fiber deposition time, instability interval, evaporation rate and the nature of the polymer, fibers with different morphology particularly porous, beaded, non-uniform or fibers with varying diameters were observed [27, 29]. Adjusting a proper polymer solution flow rate is important as it remarkably affects the transfer of the material and also the velocity of the jet during electrospinning. This will subsequently influence the pore diameter and fiber diameter of the nanofibers deposited [29]. The surface tension and viscosity of the polymer solution jet varies with concentration of the polymer solution [25]. An optimum concentration is essential for the fabrication of uniform and defect free ultrafine fibers. There were various reports on the occurrence of electrospraying process at very low concentrated solutions. Electrospinning was reported to be not convenient at very high concentration which results fibers with large average diameter [30-32]. Solvents play an important role during the entire process of fiber formation from solution preparation to fiber collection. The capacity to dissolve the polymer, its volatility, boiling point and charge carrying capacity have combined effect over electrospinning. The vapor pressure and the dipole moment of the solvent determine the rate of evaporation and conductivity of the polymer jet. The high dipole moment of the solvent influences the surface morphology and average diameter of the fibers [33-36].

Among a large number of promising engineering materials polycarbonate (PC) garnishes a key position with its unique mechanical and physical properties. It is a material with excellent heat resistance, resistance to acid and alkali, impact strength, rigidity, toughness and stable performance in high temperature atmospheres [34, 37]. The above mentioned properties of PC enable it to be a suitable material for filtration, bio-medical, electronics, protective clothing and many other modern applications [38]. Only limited number of studies were done to prepare micro and nano sized fibers of PC by electrospinning technology. Various electrospinning parameters and their influence on the final morphology of the polymer fibers were also reported [39-45]. As it is an amorphous material, it has the ability to possess high residual charge by electrospinning. Preparation of antimicrobial filtration membranes of PC were reported by electrospinning with the addition of quaternary ammonium salt into the polymer matrix [46]. Ultrafine PC fibers were prepared by the addition of hexadecyl trimethyl ammonium bromide (CTAB) with average pore size $504 \mathrm{~nm}$ and average diameter of $319 \mathrm{~nm}$ with high efficiency [47].

The present study systematically established the preparation of ultrafine beadless PC fibers with average diameter of $90 \mathrm{~nm}$. Fixed concentration of PC solutions were electrospun by varying the solvent proportion, flow rate, applied voltage and distance between the needle tip and the collecting plate (working distance). The surface morphology and average diameter of the generated fibers were thoroughly investigated. The uniform bead free fiber mat with least average diameter was further examined for its filtration ability. 


\section{Experimental}

\section{Materials and methods}

Polycarbonate (PC) pellets were purchased from Sigma Aldrich, USA with molecular weight 45,000 g/mol. Analytical grade solvents dichloromethane (DCM) and $N$, $N$ dimethyl formamide (DMF) were procured from Merck India Ltd.

\section{Electrospinning}

In our previous published papers different concentrations of PC in the solvents DCM and DMF were electrospun under constant spinning parameters [32, 34]. A $14 \mathrm{w} / \mathrm{v} \%$ PC solution in 1:1 DCM-DMF mixture was found to generate beadless fibers with least average diameter of $90 \mathrm{~nm}$. So in the present work the PC concentration was kept constant as $14 \mathrm{w} / \mathrm{v} \%$ and varied the solvent ratio and other spinning parameters. Electrospinning of PC solutions were done with the help of Espin Nano electrospinning machine supplied by PECO Chennai. The process of formation of fiber mat during electrospinning of PC solution is shown in Fig. 2a. The solution was taken in a $5 \mathrm{~mL}$ syringe with needle $0.6 \times 25 \mathrm{~mm}^{2}$ dimension and connected to one of the electrode. The other terminal was connected to the fiber collecting metal plate. Then voltages of 10, 20 and $30 \mathrm{kV}$ were separately applied to $14 \mathrm{w} / \mathrm{v} \%$ PC solutions keeping all other parameters constant. Similarly electrospinning continued by varying the flow rate as $0.5,1$ and $1.5 \mathrm{~mL} / \mathrm{h}$. Then the process was repeated by setting the needle tip-collection plate distance as 10,15 and $20 \mathrm{~cm}$. Five different proportions of solvents were experimented with values $1: 1,3: 2,7: 3,4: 1$ and 9:1. The conductivities and viscosities of these solutions were measured with the help of Eutech instruments Cyberscan PC 300 model conductivity meter and Brookfield digital viscometer CAP 2000 with spindle number 1 respectively. The collected fibers were characterized for surface morphology with the help of TESCAU VEGA 3 SBH scanning electron
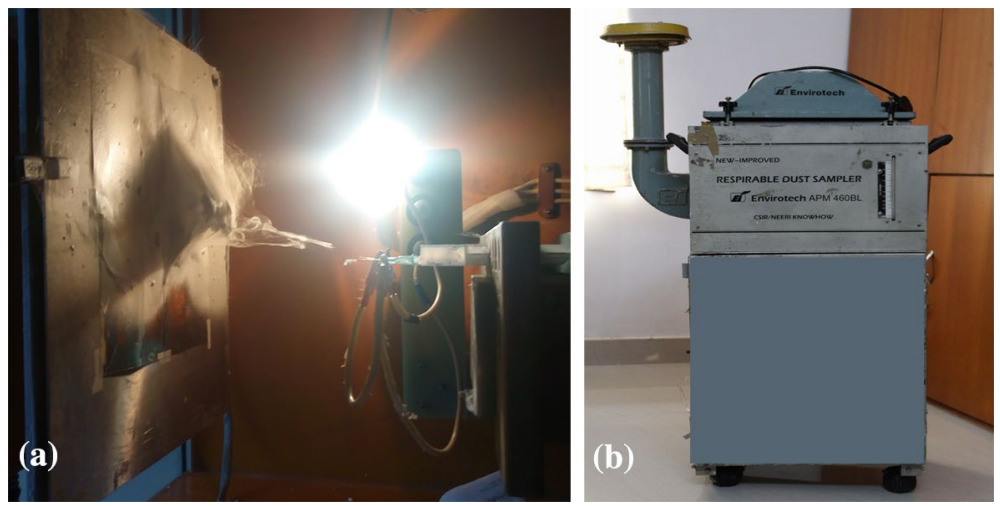

Fig. 2 a Formation of PC fiber mat during electrospinning. b Respirable dust sampler for particulate matter analysis 
microscope (SEM). The water contact angles of the prepared fibers were measured using DMS 401 contact angle instrument.

\section{Respirable dust sampler}

The filtration property of PC nanofiber mat produced by electrospinning process was measured with the help of Envirotech APM 460BL Respirale dust sampler (Fig. 2b).

The indoor air pollutants were collected from the kitchen premises of a household on a busy time schedule between 8 am and 12 noon for two consecutive days. A $20.3 \times 25.4 \mathrm{~cm}(1 \times 8$ in.) glass fiber filter paper was used to collect particles. The adsorbed respirable suspended particulate matter (RSPM) will spread over about $18 \times 23 \mathrm{~cm}$ area of the glass fiber filter paper after exposure. Loosen the face plate wing nuts and remove the face plate of instrument. Remove the weighed filter paper from its jacket and center it on the support screen with the rough side of the paper facing upward. Replace the face plate and tighten the wing nuts. Set the timer for $2 \mathrm{~h}$ for continuous sampling. After sampling was completed, note the final flow rate by removing the wing nuts. Folded the filter in half-length by handling it along its edge with the exposed side inward. Weighed the filter paper after proper drying. Weighed another glass fiber filter paper and placed inside the chamber as discussed above. Then the prepared PC fiber mat was kept over the gap on one side of the instrument which is in between the glass fiber paper and the external sucking hood. Tighten all the screws ensuring the suction of the particulate matter properly through the fiber mat. The experiment was conducted by maintaining the time and atmosphere same as the first one. The process was repeated with fresh glass papers and fiber mat for the next $2 \mathrm{~h}$. The experiment was also done by using PC fiber mats with different thickness.

The histograms of the nanofibers were prepared by using a custom code Image $\mathbf{J}$ software. A suitable SEM image was selected, set the scale and selected a scanned area of the image. Along with the histograms average fiber diameter and standard deviation values will be available. The standard deviation values will provide an insight into the variation of fiber uniformity. The bead density of the fibers was also calculated using this software.

\section{Results and discussion}

Polycarbonate (PC) was perfectly soluble in the solvent DCM but slightly soluble in DMF. Fibers with least average diameter was obtained for $14 \mathrm{w} / \mathrm{v} \%$ PC in 1:1 DCM-DMF mixture out of a series of different concentrations experimented [34]. The average fiber diameter increases with increase in the concentration of the polymer solution. This is attributed to the increase in viscosity that can strongly opposes the bending instability of the polymer jet [48]. To confirm whether this PC concentration could produce beadless uniform fibers with least average diameter by the variation of solvent proportion, flow rate, applied potential and needle tip-collector distance, systematic investigations were performed. 


\section{Variation in solvent proportion}

Different proportions of the solvents DCM and DMF were examined at constant PC concentration and spinning parameters. Both solvents in PC solutions have their own active role to modify and balance various forces acting on the polymer jet during its flight to the target [42]. Various spinning parameters applied for different solvent proportions during electrospining are provided in Table 2. The SEM images of the fibers obtained by the electrospinning of $14 \mathrm{w} / \mathrm{v} \%$ of PC in different solvent proportions are given in Fig. 3 .

Beadless fibers with slight variation in uniformity and average diameter were obtained from all the solvent proportions. $14 \mathrm{w} / \mathrm{v} \%$ of PC in 1:1 DCM-DMF mixture has generated uniform fibers with an average diameter of $90 \mathrm{~nm}$ (Fig. 3a). For 3:2 solvent mixture beadless PC fibers with an average diameter of $388 \mathrm{~nm}$ were obtained. The average fiber diameter is $583 \mathrm{~nm}$ for PC in 7:3 DCM-DMF solvent system. Non-uniform but beadless fibers with average diameter $752 \mathrm{~nm}$ can be observed for PC in a 4:1 solvent mixture. For a 9:1 solvent system nonuniform fibers with average diameter of $816 \mathrm{~nm}$ and beadless morphology were obtained. The histograms drawn with the help of Image $\mathbf{J}$ software can easily predict the variation of uniformity of the electrospun fibers (Fig. 4). The corresponding standard deviation (SD) values of average diameters are also provided along with the histograms.

The variation in uniformity of the nanofibers obtained from different solvent proportions can be identified from the standard deviation values. This was an interesting observation that the average diameter and non-uniformity increased with decrease of DMF concentration. The large dipole moment possessed by the solvent DMF helps to maintain a high charge density to overcome the surface tension exerted in the polymer jet [34]. Volatile solvent like DCM supports faster dehydration of the nanofibrous mat deposited on the target [49]. So PC solution with higher proportion of DCM caused the formation of non-uniform fibers with
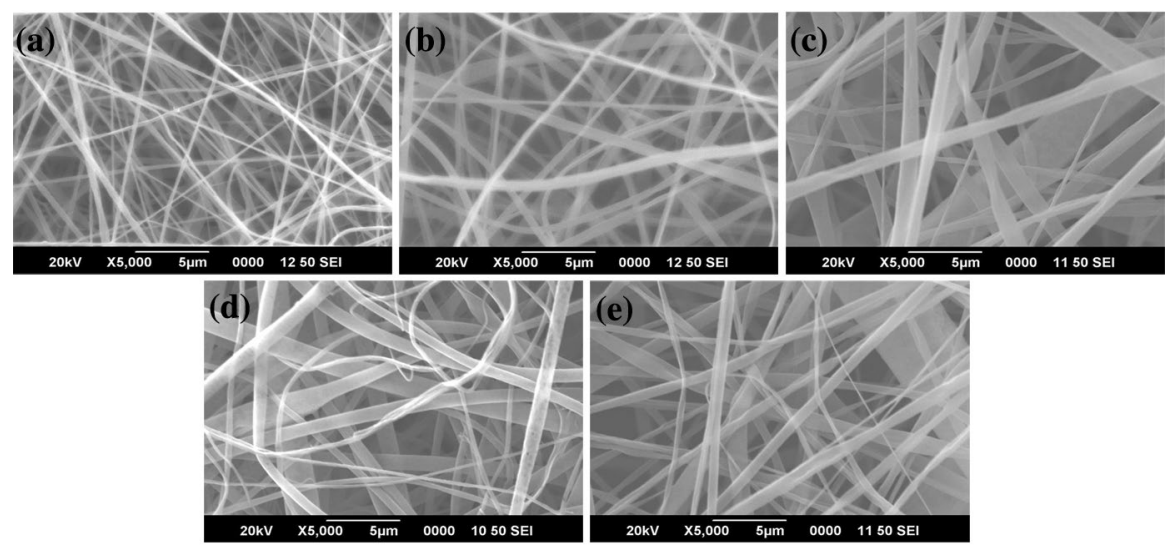

Fig. 3 SEM images of fibers of $14 \mathrm{w} / \mathrm{v} \%$ of PC in various proportions of DCM-DMF mixture a 1:1, b $3: 2$, c $7: 3$, d $4: 1$ and e $9: 1$ 


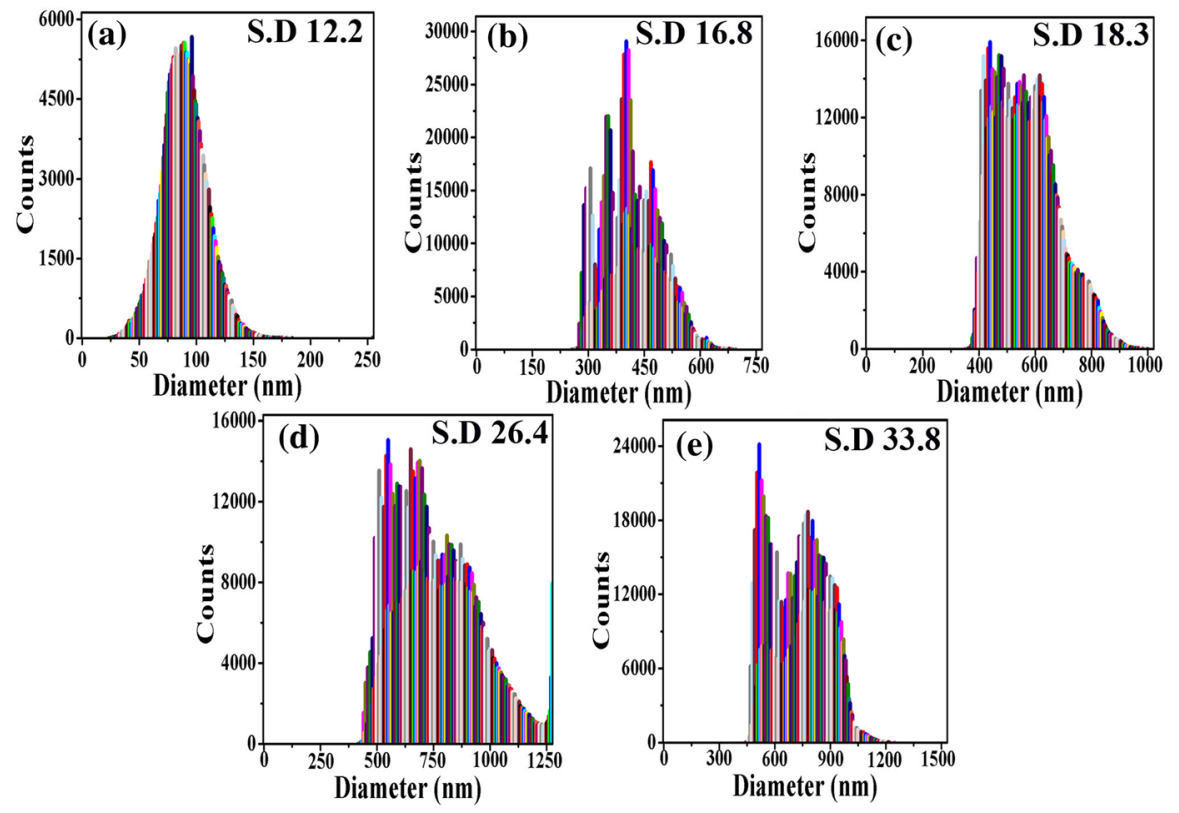

Fig. 4 Histograms of the fibers of $14 \mathrm{w} / \mathrm{v} \%$ of PC in various proportions of DCM-DMF mixture a 1:1, b $3: 2$, c 7:3, d 4:1 and e 9:1. Corresponding standard deviation (SD) values in nanometer are provided in each image

large average diameter. The solution viscosities and conductivities of $14 \mathrm{w} / \mathrm{v} \% \mathrm{PC}$ in different solvent proportions are provided in Table 1.

With the increase of DCM content in the solvent mixture, solution viscosity increased gradually. Meantime the solution conductivity decreased with increase of DCM content in the mixture. The relation between viscosity of the PC solutions and the corresponding values of average diameters is in good agreement with various previous reports. With the increase of DMF content viscosity of the solution decreases and conductivity increases. All these factors together affected the final morphology of PC fibers including uniformity. The variation of average diameter of PC fibers with different solvent proportions is given in Fig. 8a.

Table 1 Solution viscosities and conductivities of $\mathrm{PC}$ with different DCM-DMF proportions

\begin{tabular}{lll}
\hline DCM-DMF ratio & Viscosity $(\mathrm{cP})$ & $\begin{array}{l}\text { Conduc- } \\
\text { tivity } \\
(\mu \mathrm{S})\end{array}$ \\
\hline $1: 1$ & 52.3 & 3.53 \\
$3: 2$ & 59.1 & 3.12 \\
$7: 3$ & 66.7 & 2.69 \\
$4: 1$ & 78.9 & 1.88 \\
$9: 1$ & 82.1 & 0.92 \\
\hline
\end{tabular}




\section{Variation in applied voltage}

The SEM images and the corresponding histograms of PC fibers obtained by the electrospinning of $14 \mathrm{w} / \mathrm{v} \%$ solution in 1:1 DCM-DMF mixture under different applied voltages are shown in Fig. 5. Other spinning parameters like flow rate and working distance were kept as $0.5 \mathrm{~mL} / \mathrm{h}$ and $15 \mathrm{~cm}$ respectively. The standard deviation (SD) values of the average fiber diameter are shown in the histograms provided.

Beaded but almost uniform fibers with average diameter of $137 \mathrm{~nm}$ were obtained under an applied voltage of $10 \mathrm{kV}$. Around $4 \%$ bead density was observed by the analysis of the SEM image using Image J software. Surface morphology of PC fibers under $20 \mathrm{kV}$ applied voltage was already studied and the SEM image and histogram are provided in Figs. 3a and 4a, respectively. Under an applied voltage of $30 \mathrm{kV}$, beadless fibers were formed with slightly non uniform appearance with an average diameter of $382 \mathrm{~nm}$.

An optimum potential was found to be suitable for obtaining uniform beadless fibers with least average diameter. An applied voltage of $10 \mathrm{kV}$ was not sufficient to overcome the surface tension of the polymer solution which results beads on fibers. Applied voltage is an important parameter that has direct influence on the fluid mechanics. Stretching and acceleration of the polymer jet depend on the applied voltage that subsequently influence final fiber morphology. Low electrical conductivity of a solution results beaded fibers due to insufficient polymer jet elongation. There were reports on the decrease in average fiber diameter with increase in electrical conductivity of the solution. Very large applied voltage often results multiple jet formation and subsequently non uniform fibers [50]. The stretching of the polymer jet under the application of a high voltage has also reduced bead formation [51]. The variation of average diameter of the PC fibers with applied voltage is shown in Fig. 8b.

\section{Variation in flow rate}

Feed rate of the polymer solution during electrospinning is a prominent element for the shaping up of final morphology of the fibers. There were reports on the reduction of fiber diameter with decrease in flow rate [42]. The SEM images and the
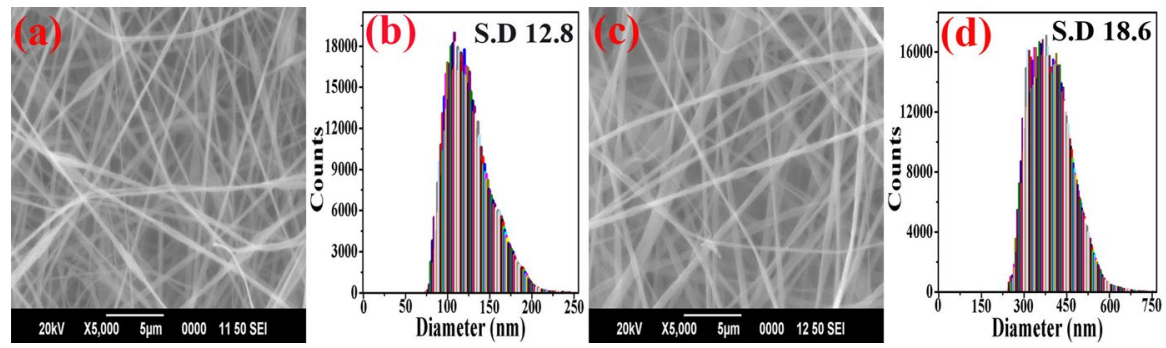

Fig. 5 a SEM image of PC fibers of $10 \mathrm{kV}$ voltage. b Histogram of PC fibers of $10 \mathrm{kV}$ voltage. c SEM image of PC fibers of $30 \mathrm{kV}$ voltage and d histogram of PC fibers of $30 \mathrm{kV}$ voltage. Corresponding standard deviation (SD) values in nanometer are provided in each image 
corresponding histograms of PC fibers obtained by the electrospinning of $14 \mathrm{w} / \mathrm{v} \%$ solution in 1:1 DCM-DMF mixture under different flow rates are shown in Fig. 6. Other spinning parameters like applied voltage and working distance were kept as $20 \mathrm{kV}$ and $15 \mathrm{~cm}$, respectively.

Almost uniform but beaded fibers with average diameters of 178 and $236 \mathrm{~nm}$ were obtained for 1 and $1.5 \mathrm{~mL} / \mathrm{h}$ flow rates respectively. Surface morphology of PC fibers under a flow rate of $0.5 \mathrm{~mL} / \mathrm{h}$ was already studied and the SEM image and histogram are provided in Figs. $3 \mathrm{a}$ and $4 \mathrm{a}$, respectively. Large spindle shaped beads were observed for the fibers obtained under a flow rate of $1.5 \mathrm{~mL} / \mathrm{h}$. Approximate bead densities of 8 and $11 \%$ were observed for the PC fibers formed under the flow rates of 1 and $1.5 \mathrm{~mL} / \mathrm{h}$, respectively. Bead formation was due to the net result of various factors during electrospinning. High flow rates were found to be not suitable for a $14 \mathrm{w} / \mathrm{v} \%$ PC solution in 1:1 DCM-DMF mixture under an applied potential of $20 \mathrm{kV}$ and a working distance of $15 \mathrm{~cm}$ to get defect free nanofibers. The polymer jet could not get enough time for complete evaporation of solvents before depositing on the target under such a high flow rate [52]. The variation of average diameter of PC fibers with the variation of flow rate is shown in Fig. 8c.

\section{Variation in needle tip-collector distance}

The distance between the needle tip and the metallic collection plate (working distance) is another important parameter that influences electrospinning of polymer solutions. The selection of an appropriate working distance depends on the type of the polymer, solution and spinning parameters. Variation of the surface morphology of the fibers obtained by changing the needle tip-collector distance was investigated by SEM analysis. SEM images and the corresponding histograms with the standard deviation values of average diameter are provided in Fig. 7.

There was considerable difference in the fiber morphology with respect to the needle tip-collection plate distance. Working distances of 10 and $20 \mathrm{~cm}$ have generated beaded fibers from a $14 \mathrm{w} / \mathrm{v} \%$ PC solution in 1:1 DCM-DMF mixture under an applied voltage of $20 \mathrm{kV}$ and flow rate of $0.5 \mathrm{~mL} / \mathrm{h}$. Non-uniform fibers with average diameters of 136 and $238 \mathrm{~nm}$ were obtained at working distances 10 and $20 \mathrm{~cm}$ respectively. An intermediate working distance of $15 \mathrm{~cm}$ was found to be
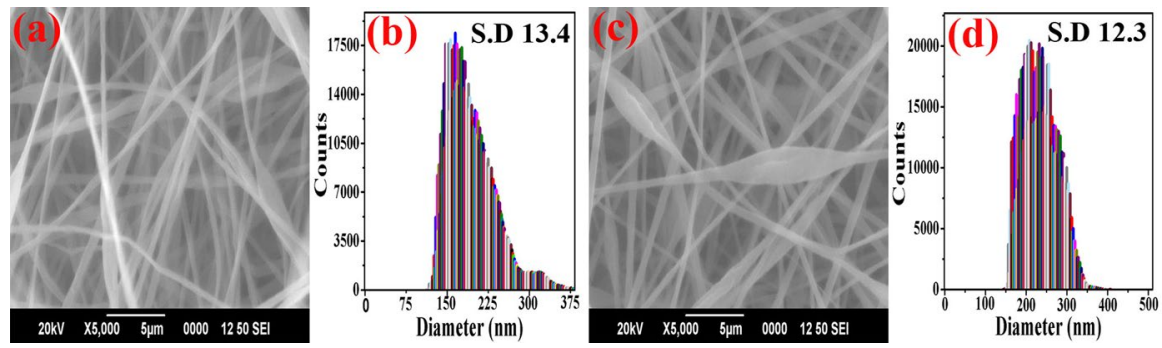

Fig. 6 a SEM image of PC fibers of $1 \mathrm{~mL} / \mathrm{h}$ flow rate. b Histogram of PC fibers of $1 \mathrm{~mL} / \mathrm{h}$ flow rate. c SEM image of PC fibers of $1.5 \mathrm{~mL} / \mathrm{h}$ flow rate and $\mathbf{d}$ histogram of PC fibers of $1.5 \mathrm{~mL} / \mathrm{h}$ flow rate [standard deviation (SD) values are provided] 

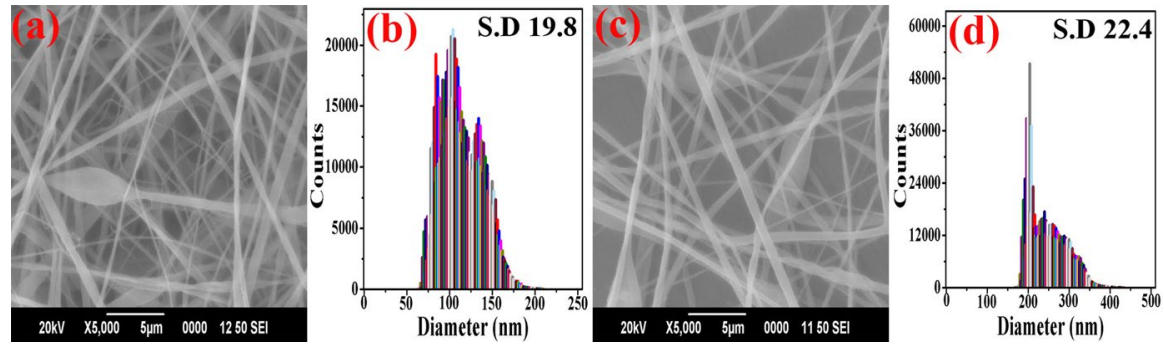

Fig. 7 a SEM image of PC fibers of $10 \mathrm{~cm}$ working distance. b Histogram of PC fibers of $10 \mathrm{~cm}$ working distance. $\mathbf{c}$ SEM image of PC fibers of $20 \mathrm{~cm}$ working distance and d histogram of PC fibers of $20 \mathrm{~cm}$ working distance [standard deviation (SD) values are provided]
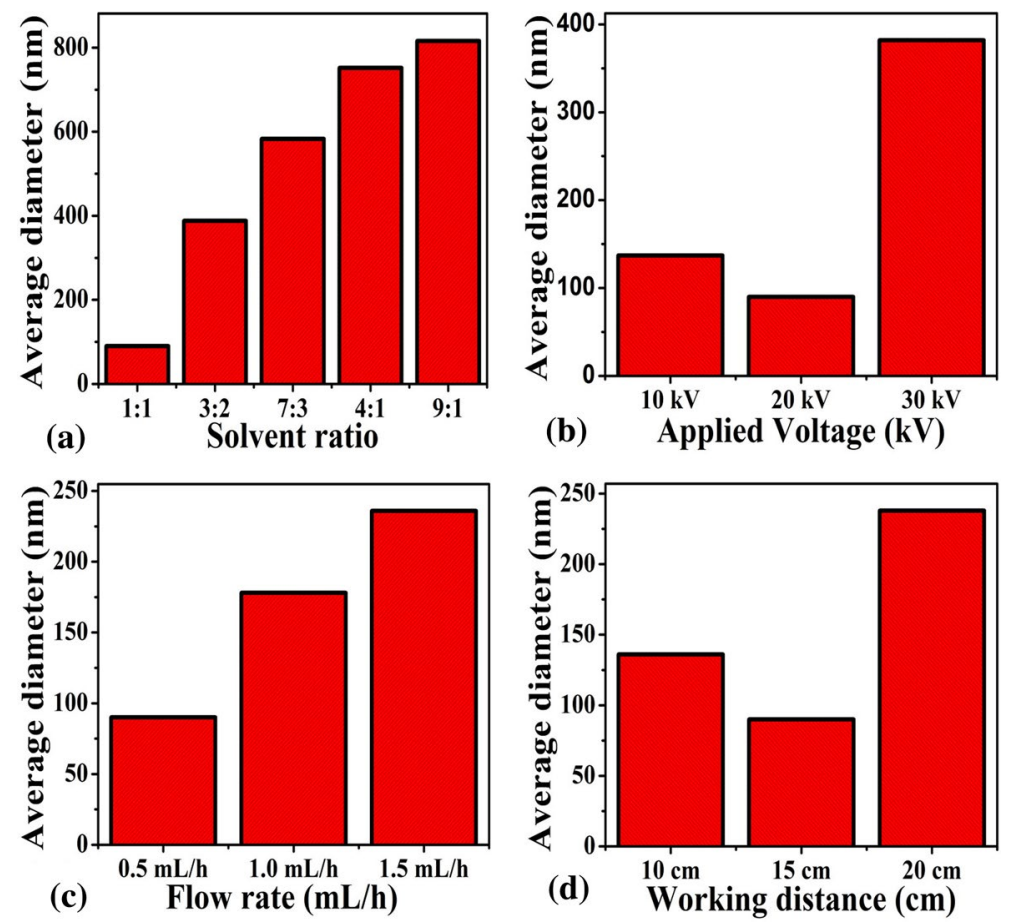

Fig. 8 The variation of average fiber diameter with a solvent ratio, $\mathbf{b}$ applied voltage, $\mathbf{c}$ flow rate and $\mathbf{d}$ working distance

most suitable for the production of uniform beadless fibers of least average diameter and the SEM image and histogram are shown in Figs. 3a and 4a respectively. Insufficient evaporation at a smaller distance was the reason for the formation of beads on fibers at a distance of $10 \mathrm{~cm}$. Early drying of the polymer jet may be the reason for the increase in average diameter and bead formation at a distance of $20 \mathrm{~cm}$. At the same time the distance tends to change the areal density due to the variation of the spread of fibers [26]. Figure 8 is given for the comparison of variation of 
average diameter of fibers produced under different solution and spinning parameters. Figure $8 \mathrm{~d}$ represents the variation of average diameter of PC fibers under different working distances.

Water contact angles are useful for the determination of wettability of polymer materials. The sessile drop method was adopted using $0.03 \mu \mathrm{L}$ water for a sample. The water contact angles of the PC fibers prepared with different solvent proportions, flow rate and needle tip-collector distance are shown in Fig. 9.

The electrospun PC fibers exhibit hydrophobic characteristics with slight variation in the water contact angle values. It was observed that the hydrophobic character was maximum for the PC fibers with least average diameter. The surface roughness of a material with lyophilic groups on the surface is inversely related to the water contact angle [53]. Superhydrophobic porous polymer membranes were reported to have high oil/water filtration efficiency [54]. PC nanofibers prepared in the solvents DCM and DMF under different solution and spinning parameters with corresponding average fiber diameter and contact angle values are given in Table 2.

Under a thorough investigation of various spinning and solution parameters on the surface morphology and average diameter of the fibers an important information was drawn. $14 \mathrm{w} / \mathrm{v} \% \mathrm{PC}$ in 1:1 DCM-DMF mixture under an applied voltage of $20 \mathrm{kV}$, flow rate $0.5 \mathrm{~mL} / \mathrm{h}$ and needle tip-collector distance of $15 \mathrm{~cm}$ were the most favorable parameters for obtaining beadless and uniform fibers with least average diameter.

\section{Indoor air pollution analysis}

Polymer fiber mat with ultrafine morphology was reported to have large surface area that enables efficient adsorption of particulate matter. PC fiber mat prepared by

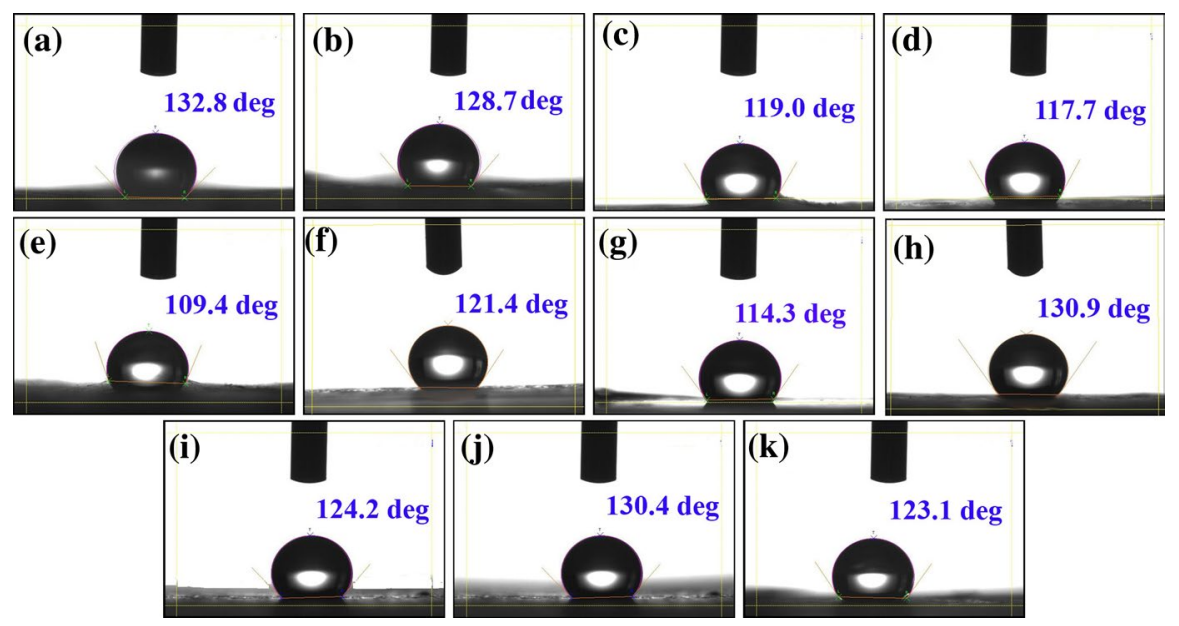

Fig. 9 Water contact angles of PC fibers prepared under different parameters a 1:1, b 3:2, c 7:3, d 4:1 and e 9:1 solvent ratios, f $1 \mathrm{~mL} / \mathrm{h}$ and $\mathbf{g ~} 1.5 \mathrm{~mL} / \mathrm{h}$ flow rates, $\mathbf{h} 10 \mathrm{kV}$ and $\mathbf{i} 30 \mathrm{kV}$ voltages, $\mathbf{j} 10 \mathrm{~cm}$ and $\mathbf{k}$ $20 \mathrm{~cm}$ working distances 
Table 2 Solution and spinning parameters used for the preparation of PC nanofibers with the corresponding fiber average diameter and contact angle values

\begin{tabular}{llllllll}
\hline Sl.no. & $\begin{array}{l}\text { Concentra- } \\
\text { tion of PC } \\
\text { solution } \\
(\text { w/v\% })\end{array}$ & Solvent ratio & $\begin{array}{l}\text { Flow } \\
\text { rate } \\
(\mathrm{mL} / \mathrm{h})\end{array}$ & $\begin{array}{l}\text { Working } \\
\text { Distance } \\
(\mathrm{cm})\end{array}$ & Voltage $(\mathrm{kV})$ & $\begin{array}{l}\text { Average } \\
\text { diameter } \\
(\mathrm{nm})\end{array}$ & $\begin{array}{l}\text { Contact angle } \\
\left({ }^{\circ}\right)\end{array}$ \\
\hline 1 & 14 & $1: 1$ & 0.5 & 15 & 20 & 90 & 132.8 \\
2 & 14 & $3: 2$ & 0.5 & 15 & 20 & 388 & 128.7 \\
3 & 14 & $7: 3$ & 0.5 & 15 & 20 & 583 & 119.0 \\
4 & 14 & $4: 1$ & 0.5 & 15 & 20 & 752 & 117.7 \\
5 & 14 & $9: 1$ & 0.5 & 15 & 20 & 816 & 109.4 \\
6 & 14 & $1: 1$ & 1.0 & 15 & 20 & 178 & 121.4 \\
7 & 14 & $1: 1$ & 1.5 & 15 & 20 & 236 & 114.3 \\
8 & 14 & $1: 1$ & 0.5 & 15 & 10 & 137 & 130.9 \\
9 & 14 & $1: 1$ & 0.5 & 15 & 30 & 382 & 124.2 \\
10 & 14 & $1: 1$ & 0.5 & 10 & 20 & 136 & 130.4 \\
11 & 14 & $1: 1$ & 0.5 & 20 & 20 & 238 & 123.1 \\
\hline
\end{tabular}

electrospinning method has superior air and water filtration ability. By the decrease of fiber diameter adsorption capability increases due to the increase of surface area. Electrospinning of $14 \mathrm{w} / \mathrm{v} \%$ PC in 1:1 DCM-DMF mixture deposited as a fiber mat which exactly functions like a filtration membrane.

The fiber mat was introduced over the slit in between the analysis chamber and the external hood of the particle dust analyzer. Particulate matter formed by the burning of firewood, coconut husk and coconut shell on a $4 \mathrm{~h}$ busy time period was used for the investigation of indoor air pollution. The glass fiber filter paper was exposed to fume with and without placing the PC fiber mat. Weights of the glass fiber filter paper before and after the experiment were taken. The photographs of the glass filter papers without and with using the fiber mat are shown in Fig. 10.

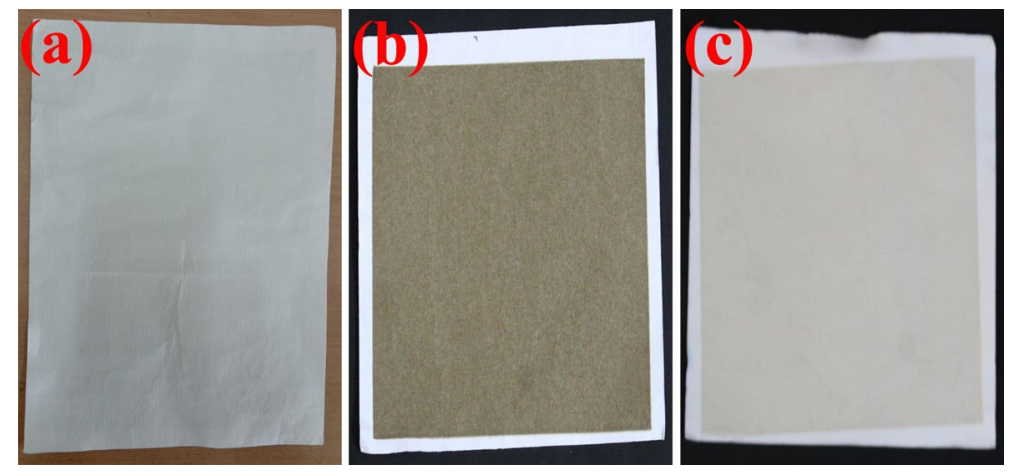

Fig. 10 Glass filter papers used for particulate matter adsorption a plane filter paper, $\mathbf{b}$ filter paper without using PC fiber mat and $\mathbf{c}$ filter paper with fiber mat separation 
The color difference of the glass fiber filter papers with and without placing the PC fiber mat in the dust analyzer shows the extent of adsorption of the air pollutants by the fiber mat. The dark color at the exposed surface of glass fiber filter paper without the use of fiber mat shows a $2 \mathrm{~h}$ continuous direct exposure (Fig. 10b). But color over the glass filter paper used with the fiber mat was reduced very much due to the adsorption of particulate matter by the fiber mat barrier (Fig. 10c). Filtration efficiency of the fiber mat is directly related to reduction in adsorption of particulate matter by the glass fiber filter paper. This was calculated using the formula:

$$
V=Q T,
$$

where $V$ is the volume of air sampled in $\mathrm{m}^{3}, Q$ is the average flow rate in $\mathrm{m}^{3} /$ minute and $T$ the total sampling time in minute. The flow rate of air was measured as $1.5 \mathrm{~m}^{3}$ per minute for $2 \mathrm{~h}$.

Mass concentration of the particulate matter less than 10 micron $\left(\mathrm{PM}_{10}\right)$ diameter was calculated by the equation:

$$
\text { Mass concentration of } \mathrm{PM}_{10}=\left(W_{\mathrm{f}}-W_{\mathrm{i}}\right) / V \text {, }
$$

where $\mathrm{PM}_{10}$ is particulate matter less than 10 micron diameter (aerodynamic diameter) and unit of mass concentration of $\mathrm{PM}_{10}$ is $\mu \mathrm{g} / \mathrm{m}^{3} . \mathrm{W}_{\mathrm{i}}$ is the initial weight and $W_{\mathrm{f}}$ the final weight of glass filter paper in $\mathrm{g}$. Mass concentration of $\mathrm{PM}_{10}$, average mass of $\mathrm{PM}_{10}$ and filtration efficiency of PC nanofiber mats with different thickness are provided in Table 3.

From the weights of glass fiber filter papers, the mass concentrations of the particulate matter deposited for $2 \mathrm{~h}$ time period with and without using fiber mat and their mean values were calculated. Finally the reduction in the deposited particulate matter was calculated from the average $\mathrm{PM}_{10}$ values. A single layer of PC fiber mat with thickness $1.64 \mathrm{~mm}$ has a filtration efficiency of $89.22 \%$. Filtration efficiency was found to increase with increase in the number of layers of PC fiber mat. But there was not much difference in the filtration efficiency of three layer and four layer fiber mats. A maximum of $93 \%$ filtration efficiency was observed for PC fiber mats with 4.33 and $5.72 \mathrm{~mm}$ thickness. It was clearly established that the PC fiber mat acts as an efficient filter for the particulate matter passing through it. This is also

Table 3 Mass concentration of $\mathrm{PM}_{10}$, average mass of $\mathrm{PM}_{10}$ and filtration efficiency of PC nanofiber

\begin{tabular}{|c|c|c|c|c|}
\hline \multirow[t]{2}{*}{ Filtration experiment } & \multicolumn{2}{|c|}{$\begin{array}{l}\text { Mass of } \mathrm{PM}_{10}(\mu \mathrm{g} / \\
\left.\mathrm{m}^{3}\right)\end{array}$} & \multirow[t]{2}{*}{$\begin{array}{l}\text { Average mass of } \\
\mathrm{PM}_{10}\left(\mu \mathrm{g} / \mathrm{m}^{3}\right)\end{array}$} & \multirow{2}{*}{$\begin{array}{l}\text { Filtration } \\
\text { efficiency } \\
(\%)\end{array}$} \\
\hline & 1 & 2 & & \\
\hline Without using PC fiber mat & 1120 & 1188 & 1154 & \\
\hline PC fiber mat with $1.64 \mathrm{~mm}$ thickness (one layer) & 124.43 & 124.21 & 124.32 & 89.22 \\
\hline PC fiber mat with $3.16 \mathrm{~mm}$ thickness (two layer) & 95.70 & 93.54 & 94.62 & 91.80 \\
\hline PC fiber mat with $4.33 \mathrm{~mm}$ thickness (three layer) & 80 & 81.66 & 80.83 & 93 \\
\hline PC fiber mat with $5.72 \mathrm{~mm}$ thickness (four layer) & 80.09 & 79.56 & 79.82 & 93.08 \\
\hline
\end{tabular}
mats with different thickness 
worth to mention that the adsorbed particulate matter coming under a hazardous class with size less than 10 microns. The images of the PC fiber mat before and after adsorption of particulate matter are provided in Fig. 11.

The entire surface of the fiber mat was covered by particulate matter including carbon. The fiber mat did not exhibit any sign of degradation. The degree of adsorption of particulate matter on the PC nanofiber mat was further investigated with the help of SEM analysis. The SEM images of the fibers with various magnifications are provided in Fig. 12.

The micrographs show that particulate matter below 10 micron was almost adsorbed and covered over the entire surface of the nanofiber mat. It was observed that PC fiber mat with least average diameter has superior particulate matter adsorption property. Such a material could successfully deliver large surface area for minute particulate adsorption.

\section{Conclusion}

The attractive properties of polycarbonate has been utilized constructively by molding it into a versatile material with large surface to volume ratio. This was done by a systematic and a novel method by the optimization of solution and electrospinning parameters. A $14 \mathrm{w} / \mathrm{v} \%$ PC was selected as the most suitable concentration from our previous research work. Suitable solvent proportion was picked from a list of different proportions of solvents with the help of electrospinning process. The selection of a solvent which has high volatility and another solvent which has large dielectric constant and dipole moment, helped to create a highly manageable electrospinning atmosphere. The interesting observation was that a solvent mixture with equal amount of these two solvents, resulted fibers which has least average diameter. Multiple experiments were conducted by varying different parameters such as
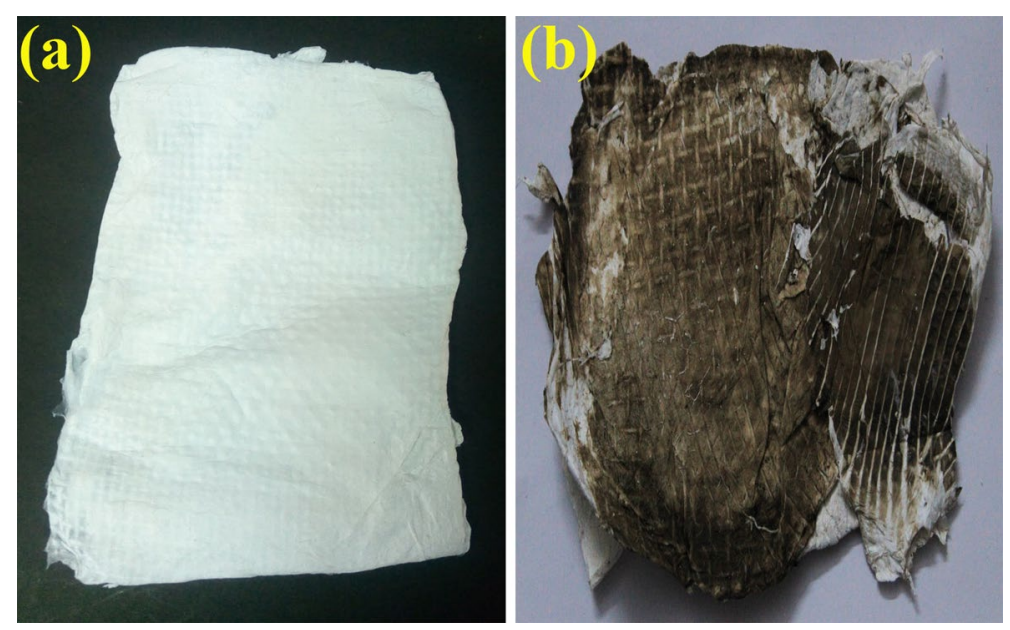

Fig. 11 PC fiber mat $\mathbf{a}$ before and $\mathbf{b}$ after adsorption of particulate matter 


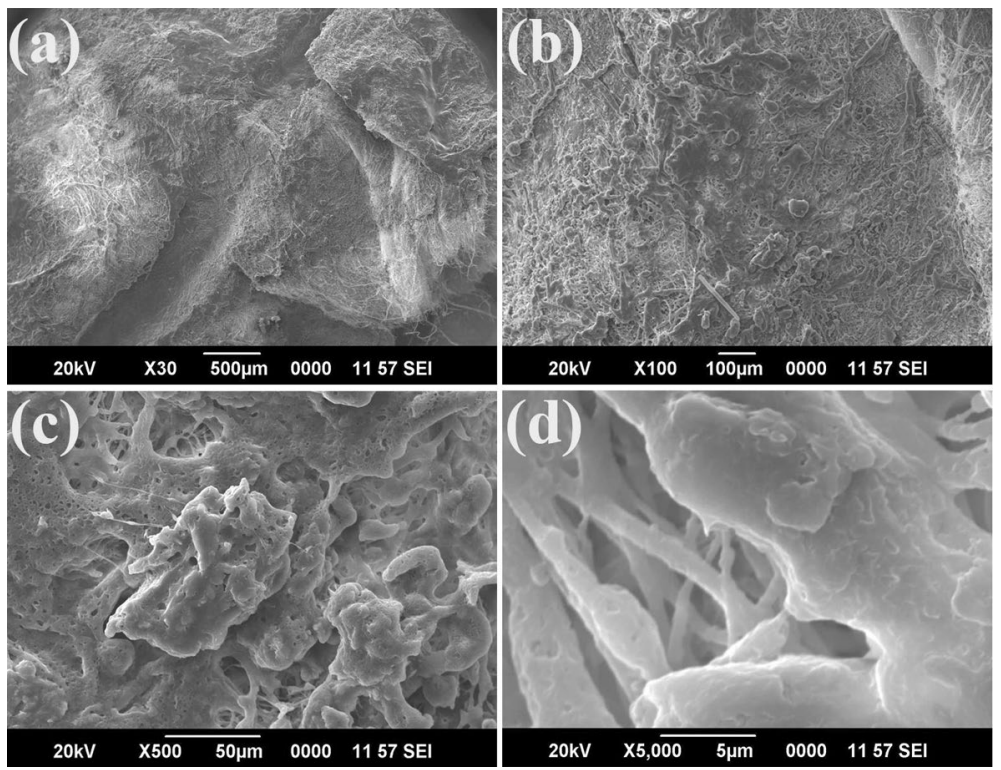

Fig. 12 SEM images of PC nanofiber mat after particulate matter adsorption with different magnifications $\mathbf{a} \times 30, \mathbf{b} \times 100, \mathbf{c} \times 500$ and $\mathbf{d} \times 5000$

the applied voltage, flow rate and needle tip-collector distance for the electrospinning of $14 \mathrm{w} / \mathrm{v} \%$ PC in 1:1 DCM-DMF mixture, and collected associated valuable information with each experiment. It is observed that a proper evaporation of the solvent and drying of the polymer jet are essential for the formation of beadless and uniform ultrafine fibers. A very low flow rate of $0.5 \mathrm{~mL} / \mathrm{h}$, medium applied potential of $20 \mathrm{kV}$ and a needle tip-collector distance of $15 \mathrm{~cm}$ were found to be the highly favorable spinning conditions. A ' $14 \mathrm{w} / \mathrm{v} \%$ PC in 1:1 DCM-DMF mixture' under the above spinning parameters has successfully generated a uniform layer of nanofibers with average diameter $90 \mathrm{~nm}$. The PC nanofiber mat exhibited excellent particulate matter adsorption capability in indoor air pollution monitoring experiment. The efficiency of the PC fiber mat was monitored by a continuous $2 \mathrm{~h}$ indoor air sample exposure. There was $93 \%$ reduction in the adsorption of particulate matter by the glass filter paper which indicates a superior filtration efficiency of the PC fiber mat with least average diameter. In the current environmental challenges this would be definitely a supportive finding in the field of air quality assessment and purification.

\section{References}

1. Chafe ZA, Brauer M, Klimont Z et al (2015) Household cooking with solid fuels contributes to ambient PM2.5air pollution and the burden of disease. Environ Health Perspect 122:1314-1320. https://doi.org/10.1289/ehp.1206340 
2. Neophytou AM, Noth EM, Liu S et al (2016) Ischemic heart disease incidence in relation to fine versus total particulate matter exposure in a US aluminum industry cohort. PLoS ONE 11:1-13. https://doi.org/10.1371/journal.pone.0156613

3. Zhang R, Liu C, Hsu PC et al (2016) Nanofiber air filters with high-temperature stability for efficient PM2.5 removal from the pollution sources. Nano Lett 16:3642-3649. https://doi.org/10.1021/ acs.nanolett.6b00771

4. Choi J, Yang BJ, Bae GN, Jung JH (2015) Herbal extract incorporated nanofiber fabricated by an electrospinning technique and its application to antimicrobial air filtration. ACS Appl Mater Interfaces 7:25313-25320. https://doi.org/10.1021/acsami.5b07441

5. Li HW, Wu CY, Tepper F et al (2009) Removal and retention of viral aerosols by a novel alumina nanofiber filter. J Aerosol Sci 40:65-71. https://doi.org/10.1016/j.jaerosci.2008.09.003

6. Zhang L, Luo J, Menkhaus TJ et al (2011) Antimicrobial nano-fibrous membranes developed from electrospun polyacrylonitrile nanofibers. J Membr Sci 369:499-505. https://doi.org/10.1016/j. memsci.2010.12.032

7. Ren X, Kocer HB, Worley SD et al (2013) Biocidal nanofibers via electrospinning. J Appl Polym Sci 127:3192-3197. https://doi.org/10.1002/app.37731

8. Leung WW (2012) Nanofiber filter facemasks and cabin filters. 2 US 8,303,693 B2

9. Zheng et al. (2016) Article containing nanofiber membrane for bacterial filtration. US 2016/0136558 A1

10. Topuz F, Satilmis B, Uyar T (2019) Electrospinning of uniform nanofibers of polymers of intrinsic microporosity (PIM-1): the influence of solution conductivity and relative humidity. Polymer (Guildf) 178:121610. https://doi.org/10.1016/j.polymer.2019.121610

11. Huang W, Cao J, Tao Y et al (2012) Seasonal variation of chemical species associated with shortterm mortality effects of PM 2.5 in Xi'an, a central city in China. Am J Epidemiol 175:556-566. https://doi.org/10.1093/aje/kwr342

12. Thakur R, Das D, Das A (2013) Electret air filters. Sep Purif Rev 42:87-129. https://doi. org/10.1080/15422119.2012.681094

13. Yoon K, Hsiao BS, Chu B (2008) Functional nanofibers for environmental applications. J Mater Chem 18:5326-5334. https://doi.org/10.1039/b804128h

14. Scampicchio M, Bulbarello A, Arecchi A et al (2012) Electrospun nonwoven nanofibrous membranes for sensors and biosensors. Electroanalysis 24:719-725. https://doi.org/10.1002/elan.20120 0005

15. Sell SA, McClure MJ, Garg K et al (2009) Electrospinning of collagen/biopolymers for regenerative medicine and cardiovascular tissue engineering. Adv Drug Deliv Rev 61:1007-1019. https://doi. org/10.1016/j.addr.2009.07.012

16. Chattopadhyay S, Hatton TA, Rutledge GC (2015) Aerosol filtration using electrospun cellulose acetate fibers. J Mater Sci 51:204-217. https://doi.org/10.1007/s10853-015-9286-4

17. Si Y, Tang X, Jianyong Yu, Ding B (2014) Electrospun nanofibers: solving global issues. Mater today 9:40-45

18. Feng C, Khulbe KC, Matsuura T (2010) Recent progress in the preparation, characterization, and applications of nanofibers and nanofiber membranes via electrospinning/interfacial polymerization. J Appl Polym Sci 115:756-776. https://doi.org/10.1002/app.31059

19. Ramakrishna S, Jose R, Archana PS et al (2010) Science and engineering of electrospun nanofibers for advances in clean energy, water filtration, and regenerative medicine. J Mater Sci 45:6283-6312. https://doi.org/10.1007/s10853-010-4509-1

20. Yeom BY, Pourdeyhimi B (2011) Aerosol filtration properties of PA6/PE islands-in-the-sea bicomponent spunbond web fibrillated by high-pressure water jets. J Mater Sci 46:5761-5767. https://doi. org/10.1007/s10853-011-5531-7

21. Zander NE, Sweetser D, Cole DP, Gillan M (2015) Formation of nanofibers from pure and mixed waste streams using electrospinning. Ind Eng Chem Res 54:9057-9063. https://doi.org/10.1021/acs. iecr.5b02279

22. Subbiah T, Bhat GS, Tock RW et al (2005) Electrospinning of nanofibers. J Appl Polym Sci 96:557569. https://doi.org/10.1002/app.21481

23. Jacobs V, Anandjiwala RD, Maaza M (2010) The influence of electrospinning parameters on the structural morphology and diameter of electrospun nanofibers. J Appl Polym Sci 115:3130-3136. https://doi.org/10.1002/app.31396 
24. Shin YM, Hohman MM, Brenner MP, Rutledge GC (2001) Electrospinning: a whipping fluid jet generates submicron polymer fibers. Appl Phys Lett 78:1149-1151. https://doi. org/10.1063/1.1345798

25. Deitzel JM, Kleinmeyer J, Harris D, Tan NCB (2001) The effect of processing variables on the morphology of electrospun nanofibers and textiles. Polymer (Guildf) 42:261-272. https://doi. org/10.1016/s0032-3861(00)00250-0

26. Basu S, Jassal M, Agrawal AK (2013) Concept of minimum electrospinning voltage (MEV) in electrospinning of PAN-DMF system: effect of distance. J Text Inst 104:158-163. https://doi. org/10.1080/00405000.2012.703797

27. Buchko CJ, Chen LC, Shen Y, Martin DC (1999) Processing and microstructural characterization of porous biocompatible protein polymer thin films. Polymer (Guildf) 40:7397-7407. https ://doi.org/10.1016/S0032-3861(98)00866-0

28. Baumgarten PK (1971) Electrostatic spinning of acrylic microfibers. J Colloid Interface Sci 36:71-79. https://doi.org/10.1016/0021-9797(71)90241-4

29. Megelski S, Stephens JS, Bruce Chase D, Rabolt JF (2002) Micro- and nanostructured surface morphology on electrospun polymer fibers. Macromolecules 35:8456-8466. https://doi. org/10.1021/ma020444a

30. Zong X, Kim K, Fang D et al (2002) Structure and process relationship of electrospun bioabsorbable nanofiber membranes. Polymer (Guildf) 43:4403-4412. https://doi.org/10.1016/S0032 $-3861(02) 00275-6$

31. Fridrikh SV, Yu JH, Brenner MP, Rutledge GC (2003) Controlling the fiber diameter during electrospinning. Phys Rev Lett 90:4. https://doi.org/10.1103/PhysRevLett.90.144502

32. Baby T, Jose ET, George G et al (2019) A new approach for the shaping up of very fine and beadless UV light absorbing polycarbonate fibers by electrospinning. Polym Test. https://doi. org/10.1016/j.polymertesting.2019.106103

33. Lee KH, Kim HY, La YM et al (2002) Influence of a mixing solvent with tetrahydrofuran and $N$, $N$-dimethylformamide on electrospun poly(vinyl chloride) nonwoven mats. J Polym Sci Part B Polym Phys 40:2259-2268. https://doi.org/10.1002/polb.10293

34. Baby T, Jose ET, Thomas PC, Mathew JT (2019) A cost effective and facile approach to prepare beadless polycarbonate nanofibers with ultrafine fiber morphology. Polym Eng Sci 59:17991809. https://doi.org/10.1002/pen.25180

35. Yang Q, Zhenyu LI, Hong Y et al (2004) Influence of solvents on the formation of ultrathin uniform poly(vinyl pyrrolidone) nanofibers with electrospinning. J Polym Sci Part B Polym Phys 42:3721-3726. https://doi.org/10.1002/polb.20222

36. Jarusuwannapoom T, Hongrojjanawiwat W, Jitjaicham S et al (2005) Effect of solvents on electro-spinnability of polystyrene solutions and morphological appearance of resulting electrospun polystyrene fibers. Eur Polym J 41:409-421. https://doi.org/10.1016/j.eurpolymj.2004.10.010

37. Mercea P (2009) Physicochemical processes involved in migration of bisphenol A from polycarbonate. J Appl Polym Sci 112:579-593. https://doi.org/10.1002/app.29421

38. Kim SJ, Nam YS, Rhee DM et al (2007) Preparation and characterization of antimicrobial polycarbonate nanofibrous membrane. Eur Polym J 43:3146-3152. https://doi.org/10.1016/j.eurpo lymj.2007.04.046

39. Yang DY, Wang Y, Zhang DZ et al (2009) Control of the morphology of micro/nano-structures of polycarbonate via electrospinning. Chin Sci Bull 54:2911-2917. https://doi.org/10.1007/ s11434-009-0241-0

40. Xu Y, Zhang X, Wang X et al (2017) Simultaneous enhancements in the strength, modulus and toughness of electrospun polymeric membranes. RSC Adv 7:48054-48057. https://doi. org/10.1039/c7ra07739d

41. Shawon J, Sung C (2004) Electrospinning of polycarbonate nanofibers with solvent mixtures THF and DMF. J Mater Sci 39:4605-4613. https://doi.org/10.1023/B:JMSC.0000034155.93428 .ea

42. Moon SC, Farris RJ (2008) The morphology, mechanical properties, and flammability of aligned electrospun polycarbonate (PC) nanofibers. Polym Eng Sci 48:1848-1854. https://doi. org/10.1002/pen.21158

43. Liao CC, Wang CC, Shih KC, Chen CY (2011) Electrospinning fabrication of partially crystalline bisphenol A polycarbonate nanofibers: effects on conformation, crystallinity, and mechanical properties. Eur Polym J 47:911-924. https://doi.org/10.1016/j.eurpolymj.2011.01.006 
44. Krishnappa RVN, Desai K, Sung C (2003) Morphological study of electrospun polycarbonates as a function of the solvent and processing voltage. J Mater Sci 38:2357-2365. https://doi. org/10.1023/A:1023984514389

45. Dhakate SR, Singla B, Uppal M, Mathur RB (2010) Effect of processing parameters on morphology and thermal properties of electrospun polycarbonate nanofibers. Adv Mater Lett 1:200-204. https:// doi.org/10.5185/amlett.2010.8148

46. Cho BM, Nam YS, Cheon JY, Park WH (2014) Residual charge and filtration efficiency of polycarbonate fibrous membranes prepared by electrospinning. J Appl Polym Sci 132:1-7. https://doi. org/10.1002/app.41340

47. Li Q, Xu Y, Wei H, Wang X (2016) An electrospun polycarbonate nanofibrous membrane for high efficiency particulate matter filtration. RSC Adv 6:65275-65281. https://doi.org/10.1039/c6ra1 $2320 \mathrm{a}$

48. Jacobs V, Anandjiwala RD, Maaza M (2010) The influence of electrospinning parameters on the structural morphology and diameter of electrospun nanofibers. J Appl Poly Sci 115:3130-3136. https://doi.org/10.1002/app.31396

49. Pillay V, Dott C, Choonara YE et al (2013) A review of the effect of processing variables on the fabrication of electrospun nanofibers for drug delivery applications. J Nanomater. https://doi. org/10.1155/2013/789289

50. Tan SH, Inai R, Kotaki M, Ramakrishna S (2005) Systematic parameter study for ultra-fine fiber fabrication via electrospinning process. Polymer (Guildf) 46:6128-6134. https://doi.org/10.1016/j. polymer.2005.05.068

51. Mazoochi T, Jabbari V (2011) Chitosan nanofibrous scaffold fabricated via electrospinning: the effect of processing parameters on the nanofiber morphology. Int J Polym Anal Charact 16:277-289. https://doi.org/10.1080/1023666X.2011.587943

52. Kulkarni A, Bambole VA, Mahanwar PA (2010) Electrospinning of polymers, their modeling and applications. Polym Plast Technol Eng 49:427-441. https://doi.org/10.1080/03602550903414019

53. Huang FL, Wang QQ, Wei QF et al (2010) Dynamic wettability and contact angles of poly(vinylidene fluoride) nanofiber membranes grafted with acrylic acid. Express Polym Lett 4:551-558. https://doi.org/10.3144/expresspolymlett.2010.69

54. Kratochvil MJ, Manna U, Lynn DM (2017) Superhydrophobic polymer multilayers for the filtrationand absorption-based separation of oil. Water mixtures. J Polym Sci Part A. 55:3127-3136. https:// doi.org/10.1002/pola.28691

Publisher's Note Springer Nature remains neutral with regard to jurisdictional claims in published maps and institutional affiliations. 